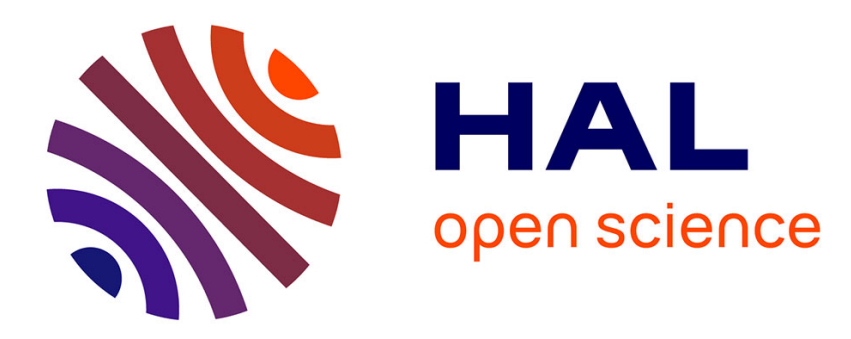

\title{
Dew, fog, drizzle and rain Water in Baku (Azerbaijan)
}

D. Meunier, D. Beysens

\section{To cite this version:}

D. Meunier, D. Beysens. Dew, fog, drizzle and rain Water in Baku (Azerbaijan). Atmospheric Research, 2016, 178-179, pp.65-72. 10.1016/j.atmosres.2016.03.014 . hal-01297478

\section{HAL Id: hal-01297478 https: / hal.sorbonne-universite.fr/hal-01297478}

Submitted on 4 Apr 2016

HAL is a multi-disciplinary open access archive for the deposit and dissemination of scientific research documents, whether they are published or not. The documents may come from teaching and research institutions in France or abroad, or from public or private research centers.
L'archive ouverte pluridisciplinaire HAL, est destinée au dépôt et à la diffusion de documents scientifiques de niveau recherche, publiés ou non, émanant des établissements d'enseignement et de recherche français ou étrangers, des laboratoires publics ou privés. 


\title{
Dew, Fog, Drizzle and Rain Water in Baku (Azerbaijan)
}

\author{
D. Meunier ${ }^{1}$ and D. Beysens $s^{1,2,3}$ \\ ${ }^{1}$ OPUR, 60 rue Emeriau, 75015 Paris (France) \\ ${ }^{2}$ Physique et Mécanique des Milieux Hétérogènes, UMR 7636 CNRS - ESPCI - Université \\ Pierre et Marie Curie - Université Paris Diderot, 10 rue Vauquelin, 75005 Paris, France \\ ${ }^{3}$ Service des Basses Températures, UMR-E CEA / UJF-Grenoble1, INAC, Grenoble 38054, \\ France
}

Email: daniel.beysens@espci.fr ph: +33140795806 fax: +33140794523

\begin{abstract}
:
Dwindling supplies of fresh water and climate changes have drawn attention to the need to find alternative sources of water globally. This study examines the potential of the semi-arid region of Baku (Azerbaijan) to exploit in particular dew, but also fog, drizzle and rain water. The Absheron Peninsular suffers from scarceness of water and non-hazardous water sources. Measurements were taken in this region on a $30^{\circ}$ inclined plane passive condenser over a year (1/4/2010-31/3/2011) to determine the contribution and validity of using these alternative sources of water. The results show an significant relative contribution from these sources during this period (rain: $84 \mathrm{~mm}$; dew:15 mm; fog: $6 \mathrm{~mm}$; drizzle: $13 \mathrm{~mm}$ ). The fact that rain was measured within $23 \mathrm{~km}$ from the main station leads to uncertainties in its relative contribution. However, at least for the year under study, there are fair indications that collecting dew, fog and drizzle in addition to rain can significantly increase the collected atmospheric water with value estimated on order $40 \pm 20 \%$.
\end{abstract}

Keywords: dew; fog; drizzle; rain; non-conventional water resources

To be submitted to: Atmospheric Research 


\section{Introduction}

Global warming and the diminution of clean fresh water in many areas of the world has made more attractive alternative source of water like rain, drizzle, fog and dew. When rain is lacking, fog can be an interesting source of water where conditions are favorable (Schemenauer and Cereceda, 1991, 1994; Cereceda and Schemenauer, 1996; Olivier and Heerden, 1999; Olivier and Rautenbach, 2002; Marzol, 2002; Marzol et al., 2008). Dew, which is passive condensation of atmospheric water vapor on a substrate exposed to nocturnal sky, is a more ubiquitous phenomenon. Several studies (Nikolayev et al., 1996; Nilsson 1996; Zangvil, 1996; Awanou et al., 1997; Kidron, 1999; Alnaser and Barakat, 2000; Muselli et al., 2002; Beysens et al., 2003, 2006; Berkowicz et al., 2004; Gandhidasan and Abualhamayel, 2005; Kalthoff et al., 2006; Sharan, 2006 and 2011; Moro et al., 2007; Kidron et al., 2011; Sharan et al., 2007, 2011; Lekouch et al., 2012; Ucles et al., 2013; OPUR, 2015; for a review see Tomaszkiewicz et al., 2015) reveal that dew in some arid or semi-arid areas cannot be neglected with respect to precipitations. There has been recent improvement in passive dew condensers construction, which now approach, under favorable meteorological conditions, the theoretical limit on order 0.8 $\mathrm{Lm}^{-2} \mathrm{day}^{-1}$ (Monteith and Unsworth, 1990; Beysens, 1995, 2006; Berkowicz et al., 2004).

Located in a semi-arid region, the Baku region (Azerbaijan) (Fig. 1) is located on the southern shore of the Absheron Peninsula, which projects into the Caspian Sea. The peninsula of Apsheron draws most of its fresh water from the Caucasus. Reserves of water per head or by square kilometre are less than those of other regions of the Southern Caucasus and the Confederation of Russia. The territory suffers from scarceness of water, especially during the dry season that lasts from June to October. Two rivers, the Kura and Araz, constitute $80 \%$ of water reserves in Azerbaijan. According to comments from the Ministry of Environment and Natural Resources of the Republic of Azerbaijan, most of the rivers that cross the country are contaminated with hazardous materials. In the capital, tap water is not potable.

The average annual rainfall is low, $200 \mathrm{~mm}$ or less. Mean relative humidity is, however, high (over $70 \%$ ) that makes drizzle a frequent phenomenon. Dew, although not referenced, also should be abundant, although strong winds, which can hamper dew formation, are frequent (Baku is known as the "city of winds").

In order to determine in Baku the potentiality of other sources of water than rain, and in particular the contributions of dew, fog and drizzle, measurements were carried out over one year (1/4/2010-31/3/2011). Although the latter were carried out for one year only, one 
nevertheless expects the results to give a significant vision of the different water contributions. The present paper reports and discuss those measurements and is organized as follows. In first section, measurements and methods are described. A second section is devoted to the evaluation of total atmospheric water with different contributions from rain, drizzle, fog and dew. Then a special section deals with the dependence of dew and fog on wind speed and direction, air relative humidity and cloud coverage. The paper ends by remarks concerning the relative contribution to atmospheric water of rain, drizzle fog and dew.

\section{Measurement and methods}

\subsection{Measurement site}

Baku is located at $-28 \mathrm{~m}$ asl and exhibits a temperate semi-arid climate (Köppen climate classification: BSk) with warm and dry summers, cool and occasionally wet winters, and strong winds all year long. Baku and the Absheron Peninsula on which it is situated, is the most arid part of Azerbaijan. Precipitation is light and around or less than $200 \mathrm{~mm}$ a year, occurring in seasons other than summer.

The measurement location ( $40^{\circ} 21^{\prime} 20^{\prime} \mathrm{N}, 49^{\circ}, 48^{\prime} 43^{\prime}, \mathrm{E}$ ) is located on a terrace of the botanical garden, in an open area (Figs. 1, 2). The terrace is $3.40 \mathrm{~m}$ off the ground. 

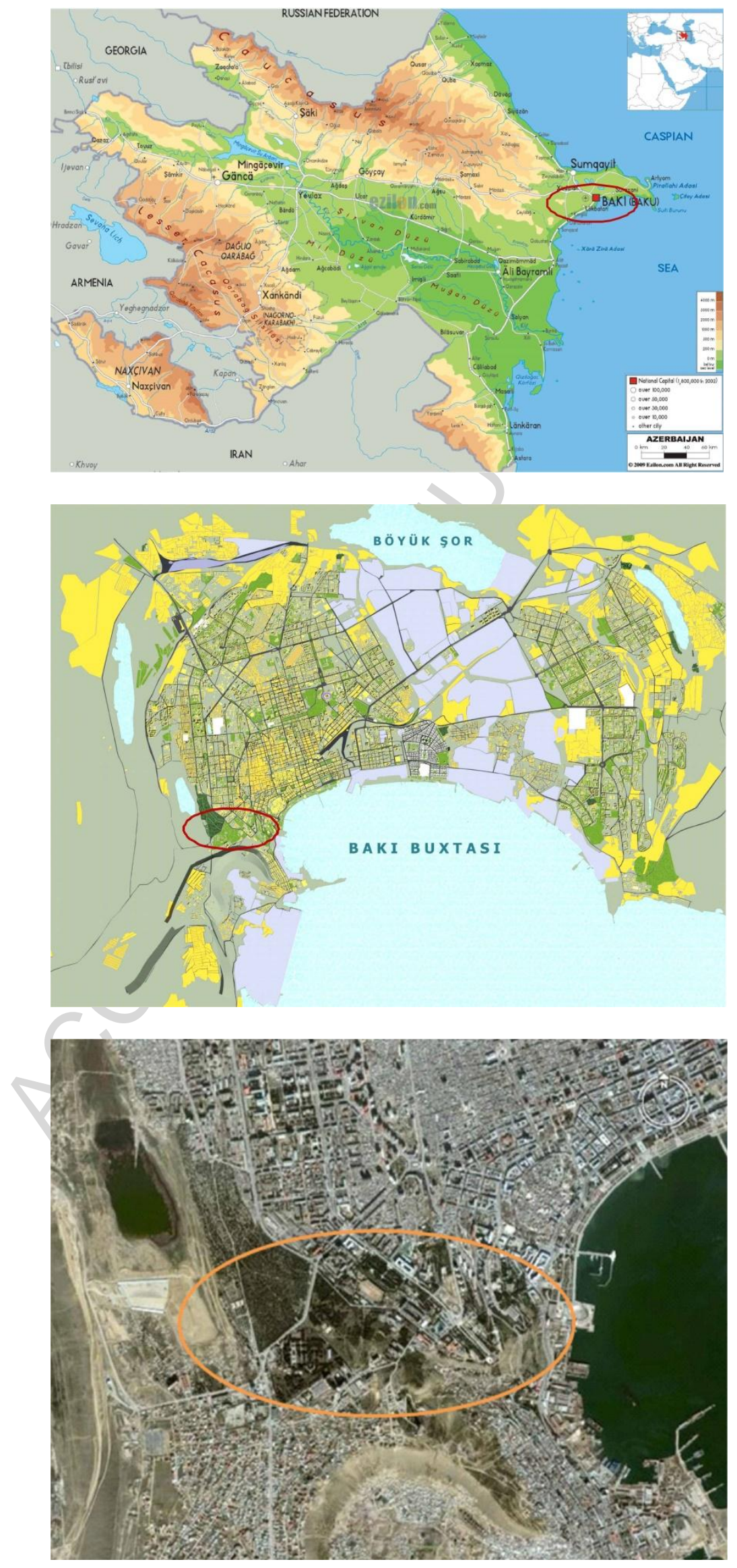

Fig. 1. Measurement site at different scales. 


\subsection{Data collection}

The condenser is the same as currently used in many other studies (Berkowicz et al., 2004, Jacobs at al., 2008; for a review see Tomaszkiewicz et al., 2015). It is constituted (Fig. 2) by a $1 \times 1 \mathrm{~m}^{2}$ plane tilted at 30 degrees with horizontal as indicated to be the "best" angle (Beysens et al., 2003). The condenser cooling surface is oriented towards South. The condenser is thermally isolated from below by $30 \mathrm{~mm}$ thick Styrofoam and equipped with an hydrophilic radiative foil of $0.35 \mathrm{~mm}$ thickness manufactured by OPUR (2015). The foil is made of low density polyethylene enclosing a few $\%$ of $\mathrm{TiO} 2$ and $\mathrm{BaSO} 4$ particles with water insoluble food proof surfactant at its surface (Nillsson, 1996). The interest of such foil lies in its enhanced dew collection ability and its chemical inert properties.

In addition to collect dew, the condenser also collects rain, drizzle and fog. The necessary corrections related to the tilt angle with horizontal (rain) or vertical (fog) are discussed below in section 2.3. Concerning fog, a vertical mesh is generally used to collect water (Cereceda and Schemenauer, 1996). The difference in yield between an inclined plate and a vertical mesh has not been studied yet in details; one only notes the study by Lekouch et al. (2012) where both devices (mesh and inclined plates) gave the same yield by units of projected vertical area.

Water is collected by gravity in a gutter and the corresponding volume is measured by a pluviometer. The resolution of water collection is $0.014 \mathrm{Lm}^{-2}$. The measurements are averaged over one hour. The pluviometer was calibrated by gently pouring different volumes of water and measuring the response of the weather station. It was found that the conversion ratio $\mathrm{mm}$-condenser / $\mathrm{mm}$-station is $8.51 \times 10^{-3}$.

An automatic weather station is placed nearby (Fig. 2). Air temperature, $T_{a}$, dew point temperature, $T_{d}$, and relative humidity $\mathrm{RH}$ are recorded every hour. An anemometer with stalling speed $0.5 \mathrm{~m} / \mathrm{s}$ and resolution $0.1 \mathrm{~m} / \mathrm{s}$ was placed at $1.5 \mathrm{~m}$ above the terrace, that is, $4.9 \mathrm{~m}$ above the ground. Wind speed $(V)$ data are averaged over one hour. We extrapolate them at $z=10 \mathrm{~m}$ height $\left(V_{10}\right)$ by using the classical logarithmic variation (see e.g. Pal Arya, 1988):

$$
V(z)=V_{10} \ln \left(z / z_{c}\right) / \ln \left(10 / z_{c}\right)
$$

Here $z_{c}$ (taken here to be $0.1 \mathrm{~m}$ ) is the roughness length leading to $V_{10}=1.18 \mathrm{~V}$. 
Cloud cover data ( $N$, in okta) are obtained visually at 5:00 hour from the Baku Heydar Aliyev Airport located within $23 \mathrm{~km}$ from the measurement site. Time is counted in UTC+4.

Rain data are also taken from the nearest meteorological station, Baku Heydar Aliyev airport. Minimum daily collected data at this site is $0.3 \mathrm{~mm}$.

As dew forms during night, daily water data collected on the condenser was chosen to be the sum of hourly data collected between dd-12:00 and dd+1-12:00. A few measurements are lacking due to unfortunate technical problems. Airport data are collected daily, from dd-00:00 to $\mathrm{dd}+1-00: 00$.

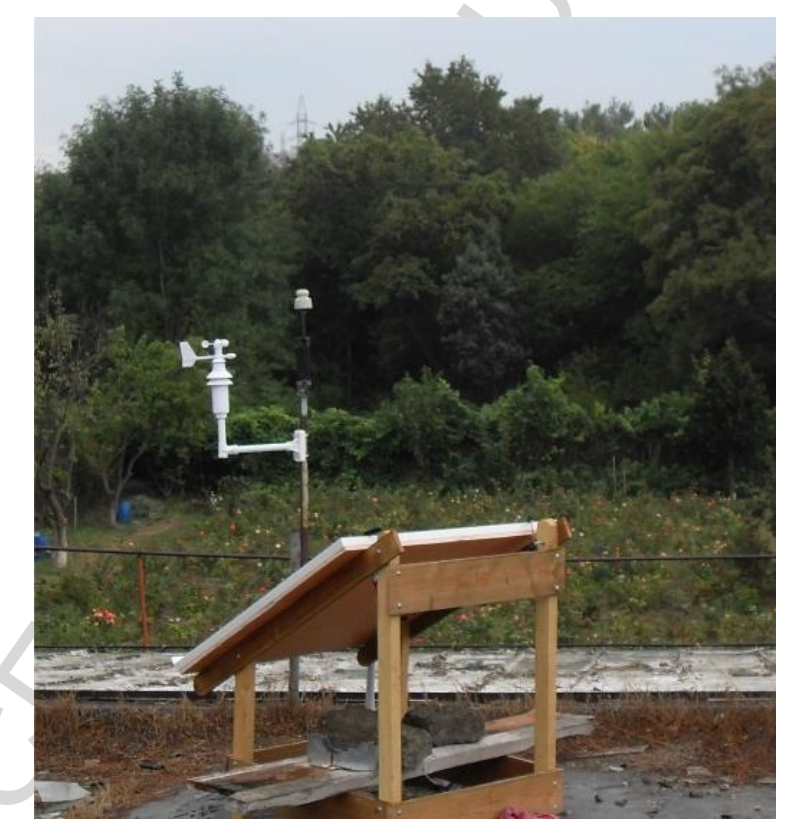

Fig. 2. Condenser and its weather station.

\subsection{Different water contributions}

The distinction between dew, fog, drizzle and rain is sometimes difficult to perform and needs some explanations. Dew occurs at night on large period of time with yields lower than $\approx 0.08$ $\mathrm{Lm}^{-2}$ hour ${ }^{-1}$. A typical recording is shown in Fig. 3, correlating dew volume with air, dew point temperatures and RH. Typically (Fig.3), dew occurs when the condenser surface temperature becomes lower than $T_{d}$. As cooling by radiative deficit is less than a few $\mathrm{K}$ below $T_{a}$, dew typically forms when $\mathrm{RH}>\approx 80 \%$. 


\begin{tabular}{c|c|c|c|c|c|c} 
Measurement & \multicolumn{3}{|c|}{$\begin{array}{c}\text { Station } \\
\text { condenser }\end{array}$} & $\begin{array}{c}\text { Airport } \\
\text { rain gauge }\end{array}$ & \multicolumn{2}{c}{$\begin{array}{c}\text { Difference } \\
\text { station - airport }\end{array}$} \\
\hline Type & Dew & Fog & All contributions & Rain & $\begin{array}{c}\text { Dew, fog \& } \\
\text { drizzle }\end{array}$ & $\begin{array}{c}\text { Drizzle } \\
\text { (threshold } \pm 2.5 \mathrm{~mm})\end{array}$ \\
\hline & & & & & & \\
\hline Sensitivity $(\mathrm{mm})$ & 0.014 & 0.028 & 0.014 & 0.3 & 0.014 & 0.3 \\
\hline $\mathrm{Nb}$ daily events & 118 & 20 & $279 / 268$ & 41 & 266 & 245 \\
\hline$h_{\min }(\mathrm{mm} /$ day) & 0.0087 & 0.017 & 0.0087 & 0.3 & -2.21 & -2.21 \\
\hline$h_{\max }(\mathrm{mm} /$ day) & 0.521 & 0.868 & 8.486 & 12.1 & 2.329 & 2.329 \\
\hline$h_{\text {mean }}(\mathrm{mm} /$ day) & 0.130 & 0.279 & 0.412 & 2.05 & 0.127 & 0.0529 \\
\hline Yearly sum $h(\mathrm{~mm})$ & 15.32 & 5.59 & 110.54 & 84 & 33.87 & 12.96
\end{tabular}

Table 1. Dew, fog, drizzle and rain characteristics at Baku (01/04/2010 - 31/03/2011). Correction is made for inclined collected surface by multiplying the collected volume by (1) $1 / \sin 30^{\circ}$ and $(2) 1 / \cos 30^{\circ}$. The yearly total sums are not exactly conserved due to differences in rain amount between station and airport, leading to uncertainty within about $15 \mathrm{~mm}$ (see text).

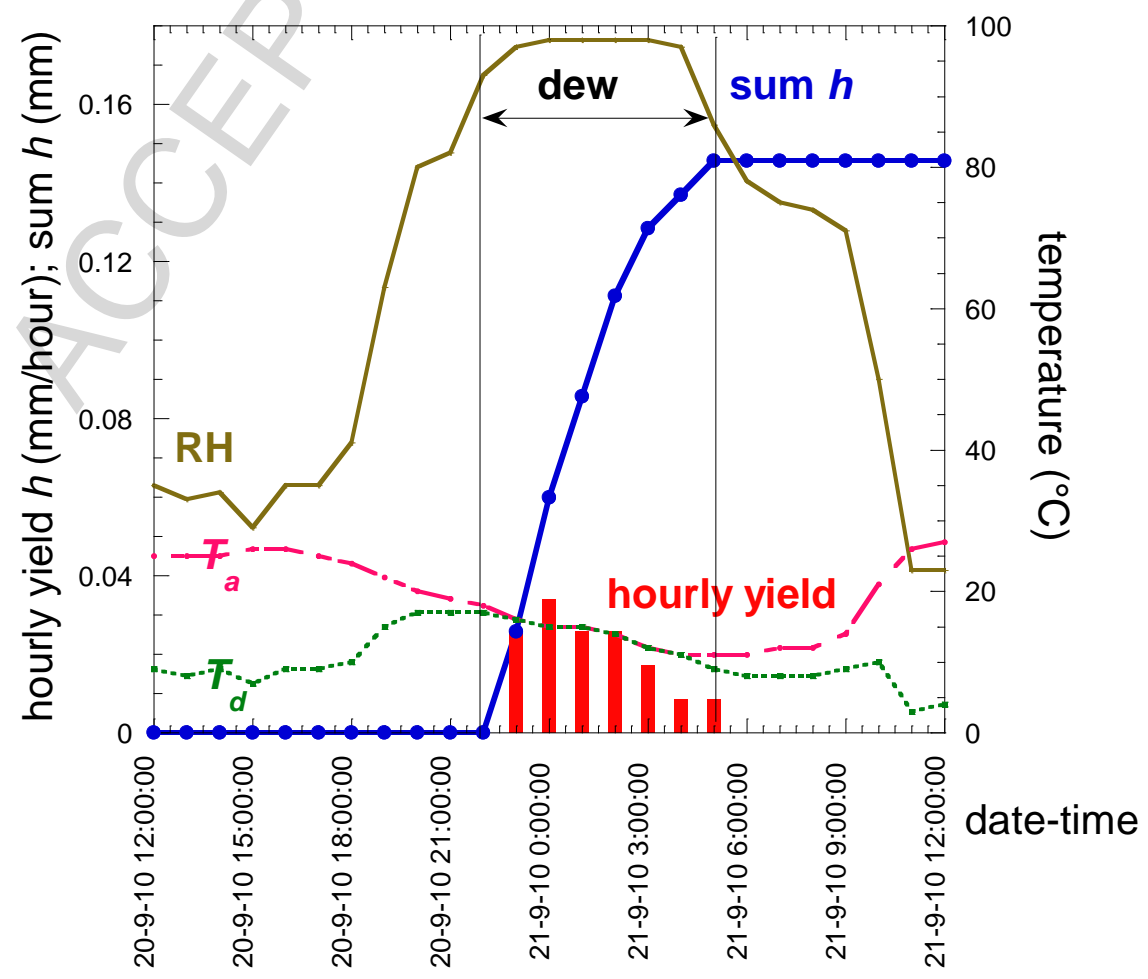

Fig. 3. Typical record for dew event (night between 20 and 21-09-2010). The bars correspond to hourly yield. Other data are indicated in the figure. Dew occurs typically for $\mathrm{RH}>\approx 80 \%$. 
Fog exhibits higher hourly yields and can occur day and night. The distinction between dew and fog can be subtle as often fog is radiative (see section 4.1 about wind dependence where it is shown that fog occurs in the same wind conditions as dew) and occurs at the end of the night. It can extend during the morning till typically noon. Nightly fog is deduced from an hourly rate larger than $0.08 \mathrm{Lm}^{-2}$ hour ${ }^{-1}$ (Fig. 4) and/or by considering visual observation at 5:00 observation. In Fig. 4 one sees a typical event where dew forms initially and is followed by fog.

Drizzle is a light precipitation that can be distinguished from rain when dew and fog contributions are determined. One can separate drizzle from rain by comparing the precipitation data at station and airport. The airport rain gauge sensitivity for precipitation is $0.3 \mathrm{~mm}$ day $^{-1}$, however the geometry and surface properties of the station collector authorizes more efficient collection.

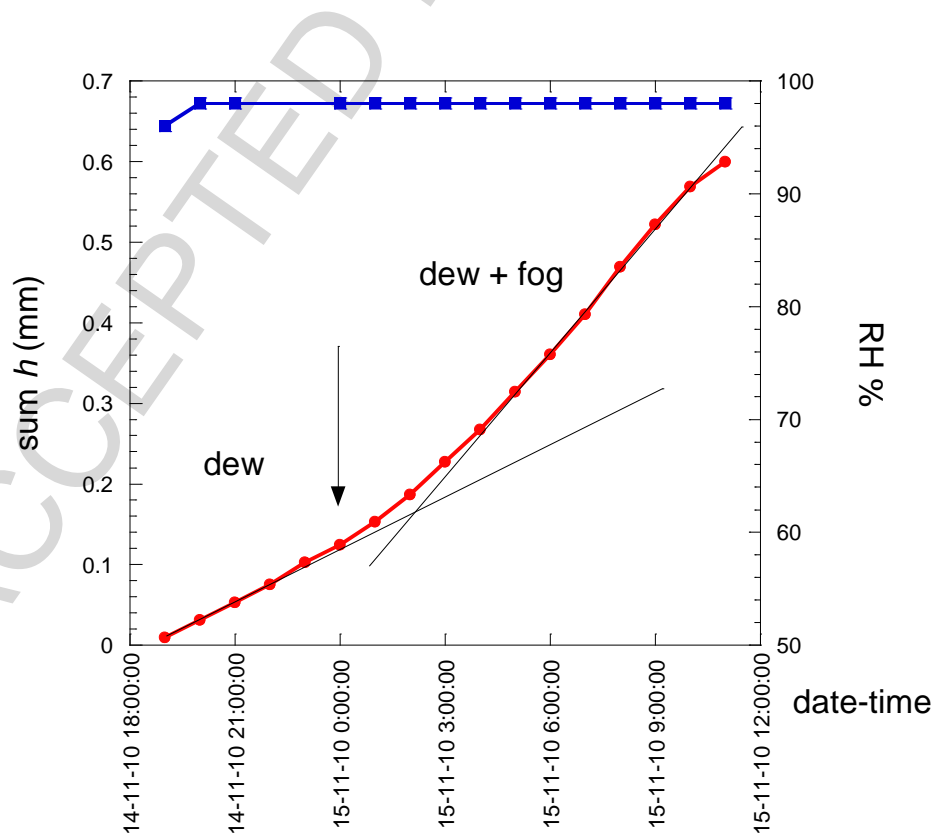

Fig. 4. Evolution of collected water, dew followed by radiative fog. The arrow separates both contributions. Left ordinate: water summation; right ordinate: relative humidity.

In order to compare dew, fog, drizzle and rain water yields, one also needs to consider the actual surface area of collection. Schematically, rain is transported vertically, fog horizontally and dew forms on the total surface area. For rain collection, the condenser collection surface 
is thus $1 / \cos \theta$, where the angle $\theta=30^{\circ}$ is the condenser tilt angle with horizontal. For fog collection, the condenser collection surface is $1 / \sin \theta$ and for dew condensation there is no correction.

From discussed just above, condenser data can thus be separated into, respectively, dew, fog and (drizzle +rain) contributions, with collection surfaces of $1,0.5$ and $0.866 \mathrm{~m}^{2}$, respectively. In order to determine the drizzle and rain contributions, one uses the airport data which are assumed to be only "rain". We thus separate the condenser water volume in $C$ (total collected water volume), $R$ (rain volume), $d$ (drizzle volume), $F$ (fog volume) and $D$ (dew volume):

$$
C=R+d+F+D
$$

In unit of volume collected by surface area (L.m ${ }^{-2}$ or mm), one has $h_{R, d}^{S}=(R, d) / \cos \theta$, $h_{F}^{S}=F / \sin \theta, h_{D}^{S}=D$, where the superscript $S$ denotes station measurements. Combining the airport data $h_{R}^{A}(\mathrm{~mm})$, where the superscript $A$ denotes airport measurement and condenser data $(C, F, D)$ at the station, one can determine the different contributions:

Dew (station):

$$
h_{D}^{S}=D
$$

Fog (station):

$$
h_{F}^{S}=\frac{F}{\sin \theta}
$$

Rain plus drizzle (station):

$$
h_{R+d}^{S}=\frac{C-F-D}{\cos \theta}
$$

The results are summarized in Table 1 and discussed in following section 4.

Drizzle determination combines station and airport data:

$$
h_{d}^{S}=\frac{C-F-D}{\cos \theta}-h_{R}^{A}
$$

The main problem when extracting drizzle volumes by subtraction is the possibility of finding negative volumes. Rain volumes can indeed be sometimes different in both station and airport sites (local showers) and day summation is also performed at different hours at station (noon) and airport (midnight). When looking at the histogram (Fig. 5) one can distinguish the effect of numerous weak variations, corresponding to a noise of amplitude of about 2-3 $\mathrm{mm}$ and 
large amplitudes due to difference in local precipitations, which ranges to about $12 \mathrm{~mm}$. In order to remove this effect, one evaluates on the drizzle summation the effect of limiting the data amplitude to a given threshold $\left( \pm h_{c}\right)$. The $h_{c}$ values are varied by steps from $12 \mathrm{~mm}$ to smaller values and one estimates the difference, $\Delta$ sum $h$, between the yearly sum and a typical date taken as 18-12-2010. It comes:

$$
\Delta \operatorname{sum} h=\operatorname{sum} h(30-04-2011)-\operatorname{sum} h(18-12-2010)
$$

The result is reported in the inset of Fig. 5. When $h_{c}$ is lowered, one observes around the value $h_{c}=2.5 \mathrm{~mm}$ strong oscillations, which correspond to the presence of large difference in station and airport precipitations. One will thus consider in the following for drizzle evaluation only drizzle data below the above $2.5 \mathrm{~mm}$ threshold value. The corresponding data are reported in Table 1 and discussed in next section 4. Note that imposing a threshold makes the yearly sums not exactly conserved when drizzle data are concerned.

Also of interest is water volume collected by the condenser from the only dew, fog and drizzle contributions, $h_{d+F+D}$ :

$$
h_{d+F+D}=h_{d}^{S}+h_{F}^{S}+h_{D}^{S}=\frac{C}{\cos \theta}-F\left(\frac{1}{\cos \theta}-\frac{1}{\sin \vartheta}\right)-D\left(\frac{1}{\cos \theta}-1\right)-h_{R}^{A}
$$
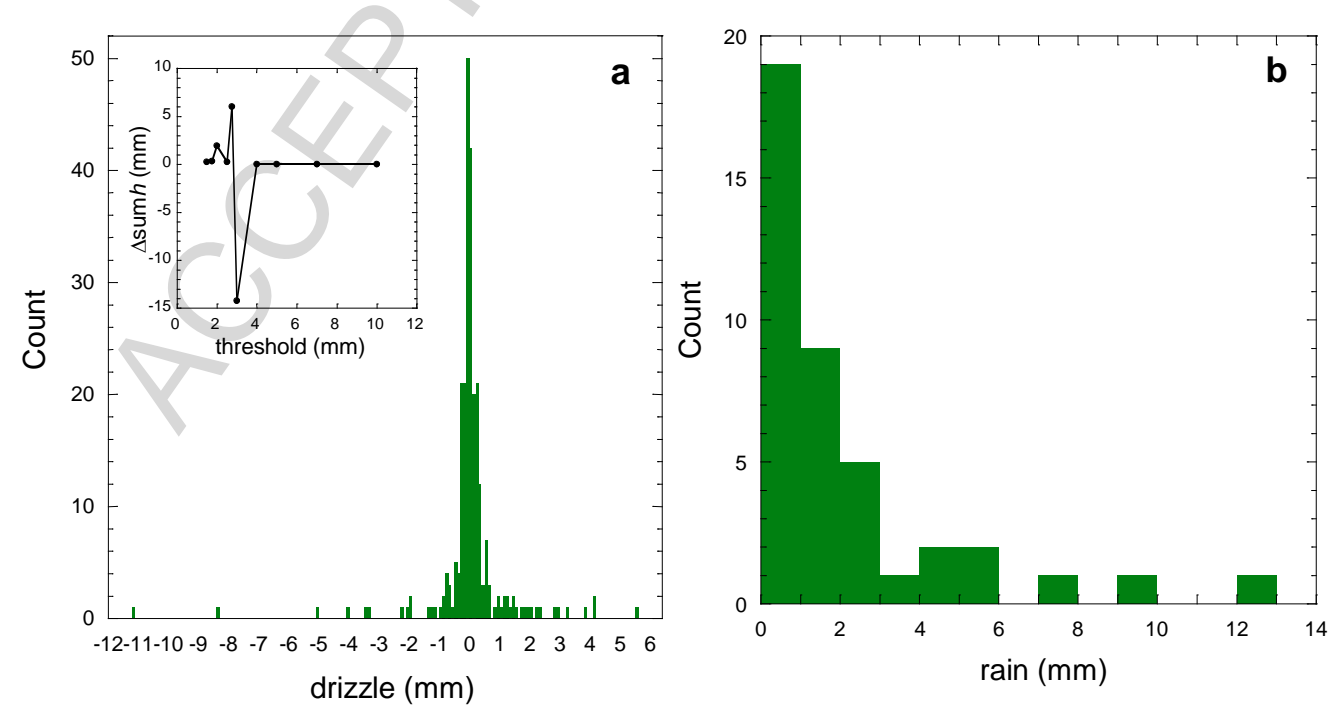

Fig. 5. (a) Histogram of drizzle contribution $h_{d}^{S}$ from Eq. 5. Inset: difference between the summation (sum $h_{d}^{S}$ ) taken on 18-12-2010 and on 30-04-2011 (yearly summation, see text).

(b) Rain histogram. 
Uncertainty on the relative contributions of rain, dew, fog, drizzle mainly comes from the different locations of rain data (airport). Although statistically the rain yield should be the same in both locations due to their vicinity, some rain events (storms) can be localized and bias the statistics. The statistics of such events can be analyzed from the rain histogram (Fig. $5 b)$. Three events of high intensity are clearly off the main body of the histogram and can be attributed to storms. It corresponds to data on 05-04-2010, $7.88 \mathrm{~mm}$ airport, $5.84 \mathrm{~mm}$ station; 26-05-2010: $12.11 \mathrm{~mm}$ airport, $4.48 \mathrm{~mm}$ station; 17-02-2011, $9.7 \mathrm{~mm}$ airport, $0.66 \mathrm{~mm}$ station. The overall difference between station and airport is $-15.6 \mathrm{~mm}$ and gives an estimation of the uncertainty in evaluating rain from airport data. It is interesting to note that all these three events give rain contribution less at station than at airport, which could mean that the relative contribution of dew, fog drizzle with respect to rain might be again more important than evaluated.

\section{Results. Discussion}

Statistics concerning dew, fog, drizzle, rain and all contributions are reported in Table 1. In Fig. 6 are shown daily and monthly evolution of dew, fog and all contributions from condenser data, and rain measurements at the airport. The yearly sums of the different contributions are shown in Fig. 7. Histograms are reported in Fig. 8. A few measurements are lacking due to technical problems. 

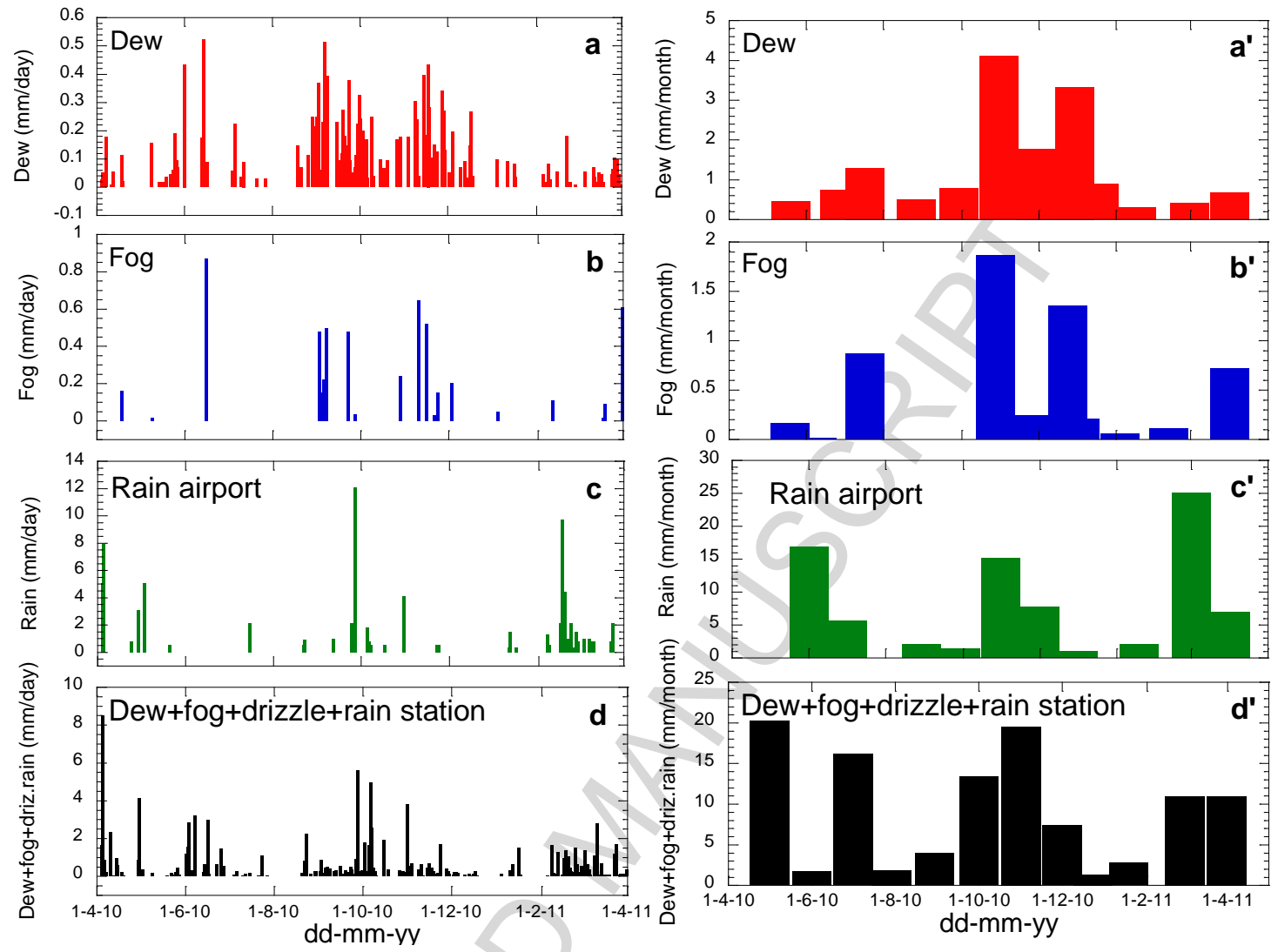

Fig. 6. Daily evolution (in mm/day) of (a) dew station, (b) fog station, (c) rain airport, (d) all contributions from station. Monthly evolution (in mm/day) of (a') dew station, (b') fog station, (c') rain airport, (d') all contributions from station.

One notices that dew forms during all year, with a large maximum in fall (from September to November) and two secondary maxima in spring (March and May-June). One observes dew during 118 days, that is, nearly $1 / 3^{\text {rd }}$ of the year. Mean and median yields are large, 0.13 and $0.09 \mathrm{~mm} . \mathrm{d}^{-1}$, respectively. A peak has been observed at $0.52 \mathrm{~mm} . \mathrm{d}^{-1}$. Concerning fog, the same kind of evolution as for dew is observed, which looks reasonable as fog is mostly radiative. Mean and median yields are 0.28 and $0.18 \mathrm{~mm}$, respectively, with a maximum at nearly $0.87 \mathrm{~mm} \cdot \mathrm{d}^{-1}$. Foggy days are less frequent than dewy days (5.5\% of the year). Rain events (11\% of the year) are more erratic, however with the same evolution tendencies as for dew. The mean rain yield is $2 \mathrm{~mm} \cdot \mathrm{d}^{-1}$, with a median close to $1 \mathrm{~mm} \cdot \mathrm{d}^{-1}$. The maximum is more than $12 \mathrm{~mm} \cdot \mathrm{d}^{-1}$. As discussed above in section 2.3, drizzle contribution is delicate to estimate since it is indirectly obtained from data taken at two different locations (Eq. 5). It is thus not impossible to sometimes obtain negative contributions. This is why we report only the summation (Fig. 7). 


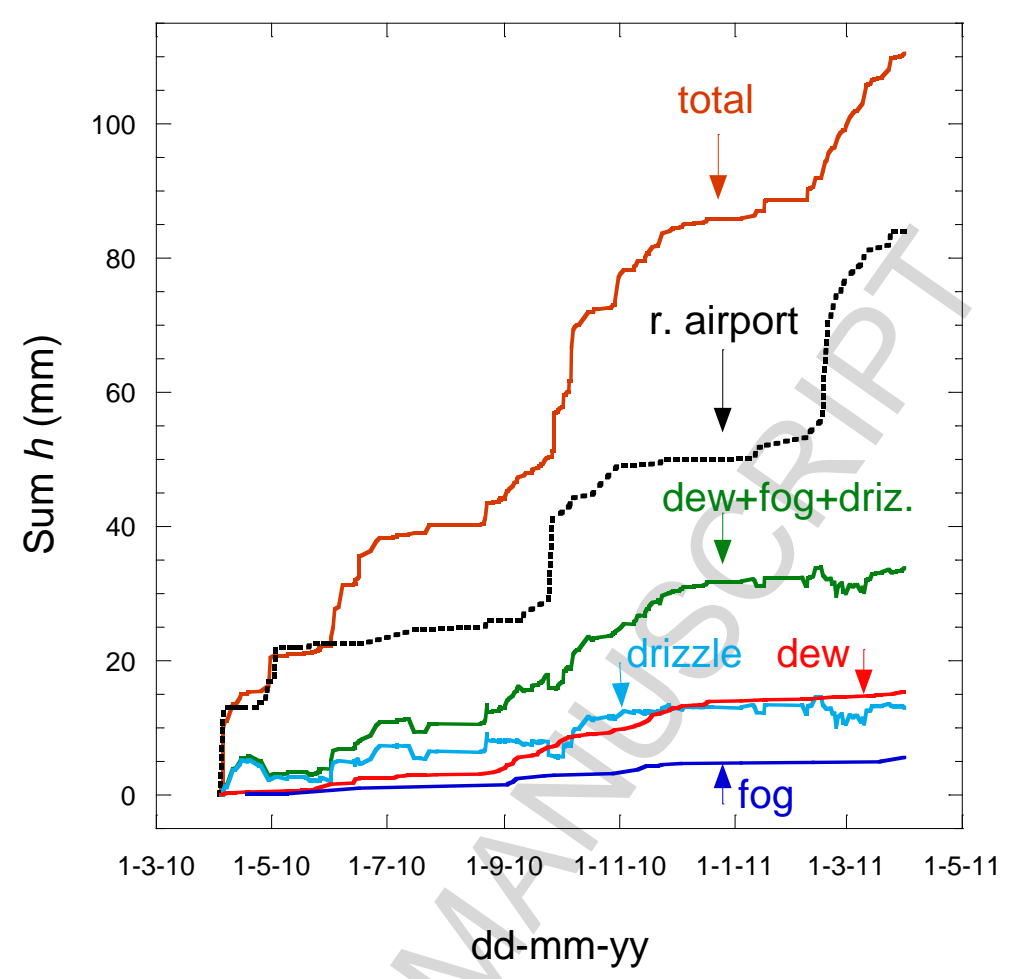

Fig. 7. Evolution of the cumulated dew, fog and rain volume (rain at airport).
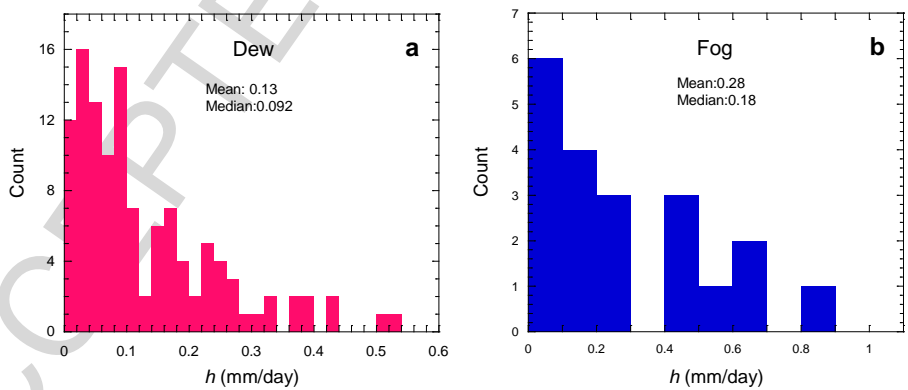

Fig. 8. Histogram of (a) dew events, (b) fog events.

Yearly water collected is about $111 \mathrm{~mm}$, corresponding to rain $(84 \mathrm{~mm})$, dew $(15.3 \mathrm{~mm})$, drizzle $(13 \mathrm{~mm})$, fog $(5.6 \mathrm{~mm})$. The amount of drizzle, fog and dew not measured by the rain collector but collectedS on the dew condenser is about $34 \mathrm{~mm}$, that is, about $40 \%$ of the rain contribution. In Fig. 9 is plotted the monthly evolution of the ratio (dew+fog+drizzle) / rain $\left(h_{d+F+D} / h_{R}\right)$. The main contribution is from September to December, with a peak of around $600 \%$ in December. 


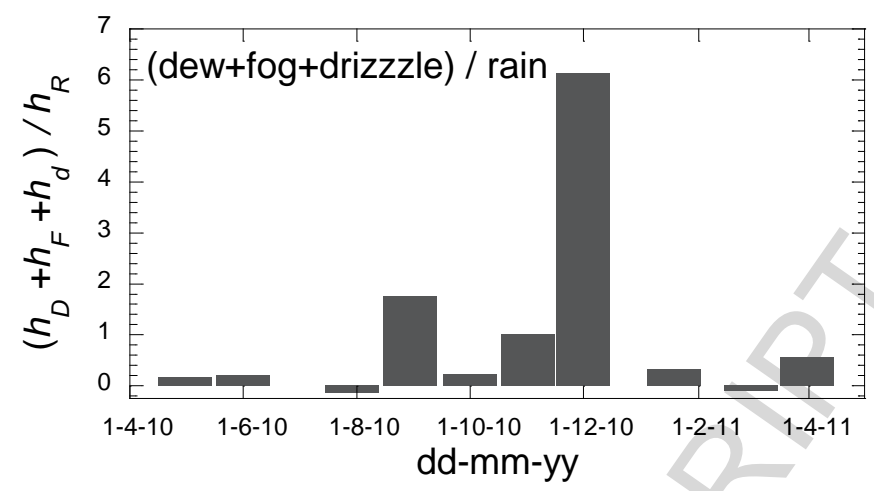

Fig. 9. Contribution of dew plus fog plus drizzle water with respect to rain water. (Notations: see text).

\section{Influence of meteorological factors on dew and fog}

In the following we address the main factors that influence the production of dew and fog: wind speed amplitude and direction, relative humidity, cloud cover.

\subsection{Wind}

Wind increases heat losses and thus hampers dew formation. Baku is a windy city. Wind is most often directed north west ( $24 \%$ of the time), south (23\% of the time), and north (23\% of the time). The cold northern wind khazri and the warm southern wind gilavar are typical here in all seasons. The wind is least often from south west (3\% of the time), west ( $4 \%$ of the time), and east (5\% of the time). In Fig. 10 are reported the wind direction dependence of hourly dew and fog events. Dew forms for all direction of winds. Fog is not observed for winds coming from east to south. 

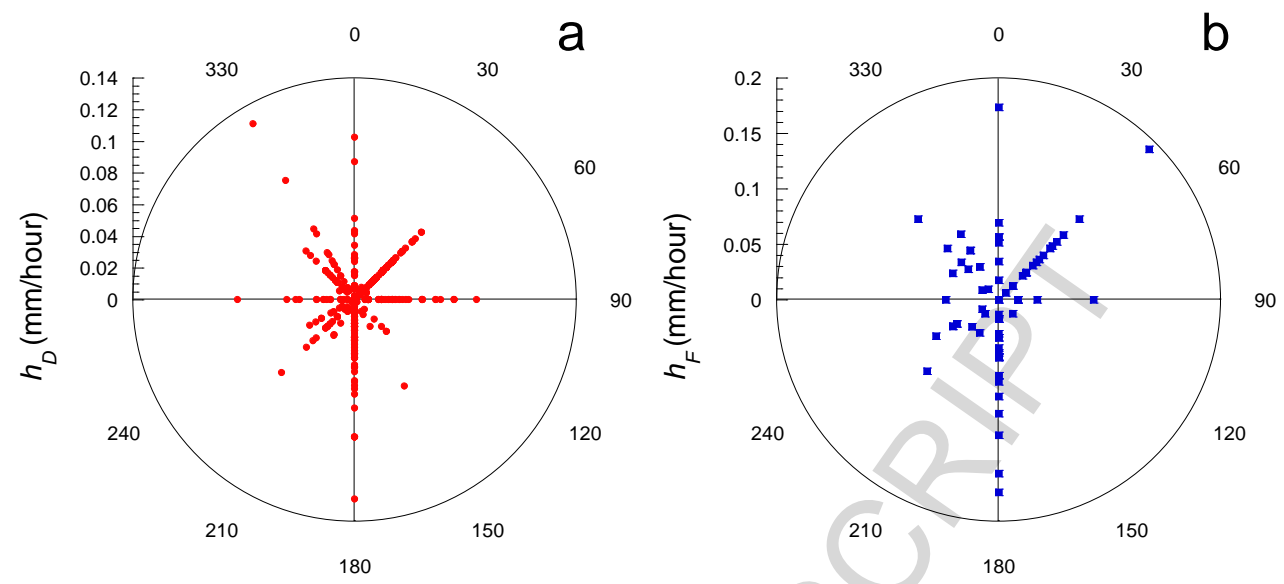

Fig. 10. Wind direction dependence of hourly (a) dew and (b) fog events.

Windspeed dependence of dew and fog is shown in Fig. 11. As it has been observed in other locations (Lekouch et al., 2012), dew rarely forms for windspeed typically more than $4.5 \mathrm{~m} / \mathrm{s}$ measured at $10 \mathrm{~m}$ above the ground. Although it is difficult to make a definitive assessment to distinguish radiative from convective fog, the correlation between fog yield and windspeed (Fig. 11) shows that fog occurs in a windspeed range similar to what is observed for dew. It could be thus mainly ascribed to radiation fog.

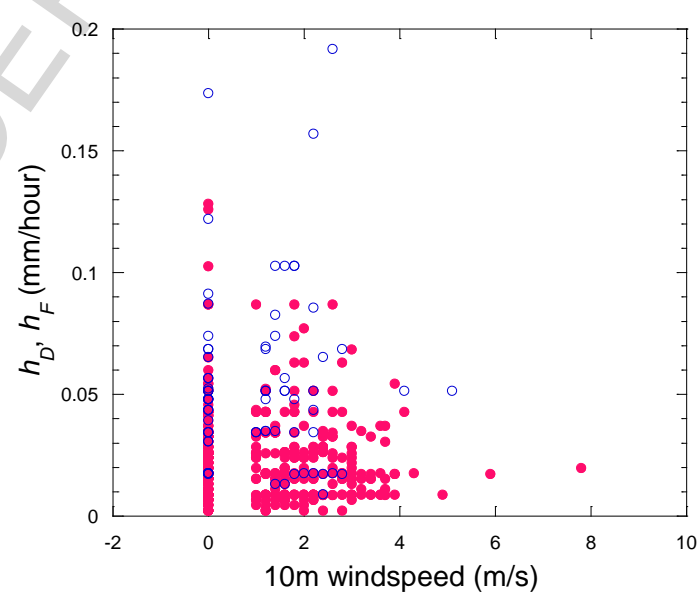

Fig. 11. Hourly dew (dots) and fog (open circles) yields with respect to windspeed at $10 \mathrm{~m}$ elevation.

\subsection{Relative humidity}

Relative humidity is a key parameter for dew (and fog) formation. As the cooling effect of the condenser surface cannot exceed a few degrees below air temperature, a high relative 
humidity is needed to have dew condensed. This situation is more favorably met during night and in early morning where air temperature is the coolest and thus relative humidity is the highest.

The occurrence of dew can be quantified by the ability of a surface to reach the dew point temperature. According to the remarks above, this condition determines a threshold in relative humidity. In Fig. 12 is reported the RH dependence of dew and fog. As noticed by Beysens et al. (2005), RH $\sim\left(T_{d}-T_{a}\right)$. Most of the data lie above $\mathrm{RH}=70 \%$, corresponding to a condenser cooling limit $\left(T_{d}-T_{a}\right) \approx-5 \mathrm{~K}$. A RH $\approx 100 \%$, corresponding to $T_{d}-T_{a}=0$, is a situation which can be encountered with either rain, fog or dew events. One notes that most fog data corresponds to very large $\mathrm{RH} \approx 98-100 \%$.

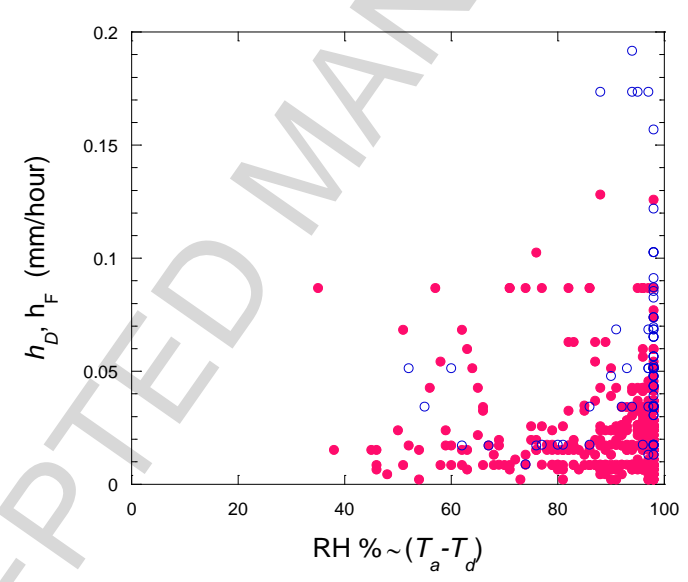

Fig. 12. Hourly dew (dots) and fog (open circles) yields with respect to $\mathrm{RH} \sim\left(T_{d}-T_{a}\right)$.

\subsection{Cloud cover}

Another parameter of importance is the cloud cover $N$ (in okta), which is a rough, but convenient, measurement of the cooling energy for dew formation. Figure 13 shows the dew yield dependence with respect to the cloud cover $N$ measured at 5:00. This time is assumed to be representative of the night cloud cover. As expected, dew yield decreases with increasing cloud cover. 


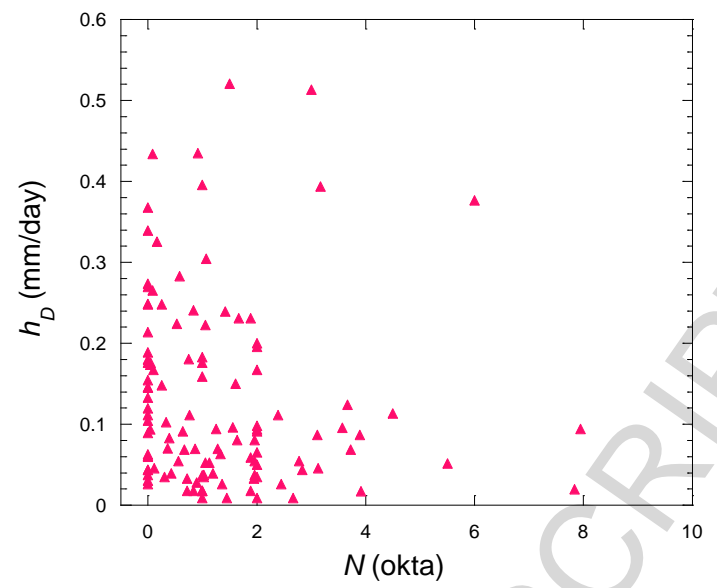

Fig. 12. Daily dew yield dependence on could coverage $N$ measured at 05:00.

\section{Dew modelling}

Dew yields within typically $30 \%$ uncertainty can be extracted from simple meteorological measurements according to an analytical model (Beysens, 2015). The model is based on the approximation of a condenser temperature at about $T_{d}$ and the recognition that most of the cooling energy is used to maintain the condenser surface at this temperature. In its simplest form where the measurement is made once per day, just before sunrise, the nocturnal yield $h$ of a condenser of $1 \mathrm{~m}^{2}$ (or similar), inclined at $30^{\circ}$ and thermally insulated from below can be written as follows:

$h=h_{0}+0.06\left(T_{d}-T_{a}\right) \times\left(1+100 \times\left\{1-\exp \left[-\left(\frac{V}{V_{0}}\right)^{20}\right]\right\}\right)$ if positive

$h=0$ if negative

The $2^{\text {nd }}$ term represents the heat losses. The $1^{\text {st }}$ term, $h_{0}$, is the cooling energy:

$$
\begin{aligned}
h_{0}= & 0.37 \times\left\lfloor 1+0.204323 H-0.0238893 H^{2}-\left(18.0132-1.04963 H+0.21891 H^{2}\right) \times 10^{-3} T_{d}\right\rfloor \\
& \times\left(\frac{T_{d}+273.15}{285}\right)^{4}(1-N / 8)
\end{aligned}
$$

The parameter $H$ is the site elevation $(\mathrm{km}) ; V$ is windspeed $\left(\mathrm{m} . \mathrm{s}^{-1}\right)$ at $10 \mathrm{~m}$ elevation. In the present experimental situation, dew is not totally collected (no scratched surface), then some corrections have to be made corresponding to the volume of water drops, $h_{s}$, that remain 
pinned at the surface. This volume is thus added in Eq. 9, and the no scratched value, $h_{n s}$, can be written as:

$$
h_{n s}=h-h_{s}
$$

The scratched value has been estimated on a $30 \mathrm{~m}^{2}$ condenser with the same tilt angle $\left(30^{\circ}\right)$ and same foil by Muselli et al. (2002). The value averaged over one year is $h_{s} \approx 0.04 \mathrm{~mm}$. Taking this value in Eq. (10), one obtains the Fig. 14 data where are reported the evolution of measured and calculated cumulated dew values. The final calculated value $(18.7 \mathrm{~mm})$ compares well with the experimental value $(15.3 \mathrm{~mm})$. In the inset is also shown the correlation between the measured cumulated dew and the no scratch calculated value. The correlation is good, with a correlation coefficient of 0.98 ( 1 expected). It remains, however, systematic discrepancies for the early (April-August) and late (February-April) months of measurements. These discrepancies relate to the lowest yields for dew (see Fig. 6) and correspond presumably to bias effects of scratch that might not be properly taken into account.

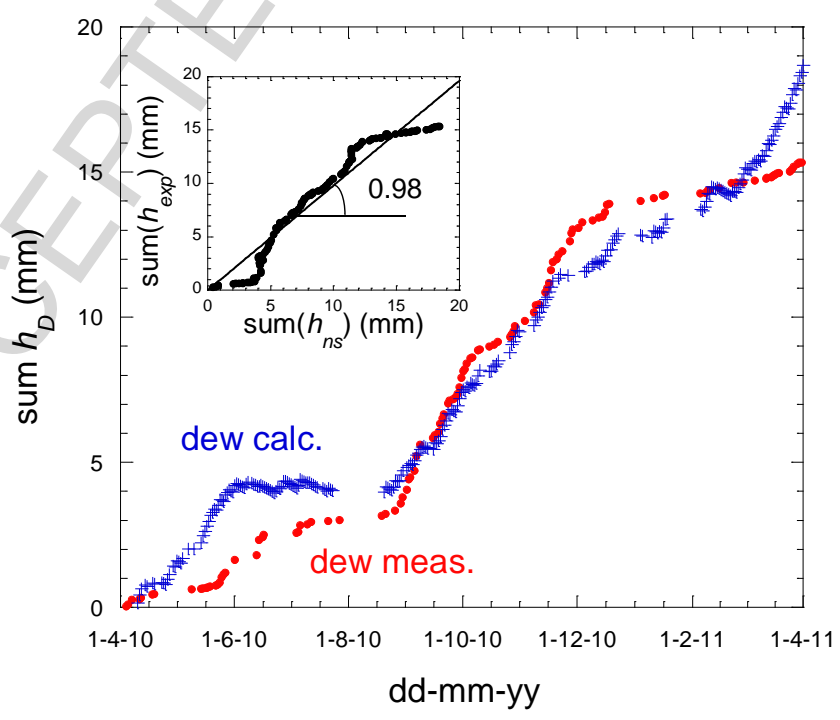

Fig. 14. Evolution of measured and calculated cumulated dew with effect of no scratch (Eqs.

9-10). Inset: correlation between measured and no scratch calculated cumulated dew.

\section{Conclusion}

Due to Baku high relative humidity, dew, fog and drizzle water collected in the studied period (1/4/2010 - 31/2/2011) provide an important contribution to atmospheric water. This contribution, not measured by current rain gauge measurements, can be evaluated to be on the 
order of $40 \%$ of rain water, with however a large uncertainty $( \pm 20 \%)$ due to the fact that rain data are collected in a close, but different location. This contribution can be different for other years as a one year statistics might be not enough representative. It is evidenced thanks to the particular water collecting properties of dew condensers that enable small water volumes to be harvested.

It then appears feasible to significantly increase the atmospheric water resources at Baku by collecting, in addition to rain, the usually neglected dew, fog and drizzle contributions. This resource can be made potable after evaluating its chemical quality. Although one cannot give its precise chemical content, previous evaluations of water quality in several parts of the world show that dew water, the most susceptible to be chemically altered because of its lowest volume, is in general potable (see e.g. Tomaszkiewicz et al., 2015). Low cost plants that collect dew, rain, drizzle and fog, in a way similar to those constructed in India (Sharan et al., 2015), could then be envisaged.

\section{Acknowledgments}

DB acknowledges support from Sorbonne-Paris-Cité Program, France.

\section{References}

Alnaser, W.E., Barakat, A., 2000. Use of condensed water vapour from the atmosphere for irrigation in Bahrain. Appl. Energy 65, 3-18.

Awanou, C.N., Hazoume, R.-P., 1997. Study of natural condensation of atmospheric humidity. Renewable Energy 10: 19-34.

Berkowicz, S., Beysens, D., Milimouk, I., Heusinkveld, B.G., Muselli, M., Wakshal, E., Jacobs, AFG, 2004. Urban dew collection under semi-arid conditions: Jerusalem. Proc. of the Third International Conference on Fog, Fog Collection and Dew, Cape Town, South Africa, Oct 11-15, 2004. pp. E4-7.

Beysens, D., 1995. The formation of dew. Atmos. Res. 39, 215-237.

Beysens, D., 2006, Dew nucleation and growth, C. R. Physique 7: 1082-1100 (2006).

Beysens, D. (2016). Estimating dew yield worldwide from a few meteo data. Atmos.

Res. 167, 146-155. 
Beysens, D., Milimouk, I., Nikolayev, V., Muselli, M., Marcillat, J., 2003. Using radiative cooling to condense atmospheric vapour: a study to improve water yield. J. Hydrol. 276, $1-11$.

Beysens, D., Muselli, M., Milimouk, I., Ohayon, C., Berkowicz, S., Soyeux, E., Mileta, M., Ortega, P., 2006. Application of passive radiative cooling for dew condensation. Energy 31, 1967-1979.

Beysens, D., Muselli, M., Nikolayev V., Narhe R., Milimouk I., 2005. Measurement and modelling of dew in island, coastal and alpine area, Atmospheric Research. 73: 1-22.

Cereceda, P., Schemenauer, R.S., 1996. La niebla: recurso para el desarrollo sustentable de zonas con déficit hidrológico. - En: Marzol, Mㄹ V., P. Dorta y P. Valladares (eds.): Clima y agua: la gestión de un recurso climático. - Madrid: 25-33

Gandhidasan, P., Abualhamayel, H.I., 2005. Modeling and testing of a dew collection system, Desalination 180, 47-51.

Jacobs, F.G., Heusinkveld, B.G., Berkowicz, S.M., 2008. Passive dew collection in a grassland area, The Netherlands. Atmos. Res. 87, 377-385.

Kalthoff, N., Fiebig-Wittmaack, M., Meissner, C., Kohlera,M., Uriarte,M., Bischoff-Gauss, I., Gonzales, E., 2006. The energy balance, evapo-transpiration and nocturnal dew deposition of an arid valley in the Andes. J. Arid Environ. 65, 420-443.

Kidron, G. J., 1999. Altitude dependent dew and fog in the Negev Desert, Israel. Agricultural and Forest Meteorology 96: 1-8.

Kidron, G. J., Temina, M., Starinsky, A, 2011. An Investigation of the Role of Water (Rain and Dew) in Controlling the Growth Form of Lichens on Cobbles in the Negev Desert. Geomicrobiology Journal: 28, 335-346.

Lekouch, K., Lekouch, M. Muselli, A. Mongruel, K. Kabbachi, Beysens, D. (2012). Rooftop dew, fog and rain collection in southwest Morocco and predictive dew modelling using neural networks. Journal of Hydrology 448-449: 60-72.

Marzol, M V. 2002. Fog Water Collection in a Rural Park in the Canary Islands (Spain). Atm. Res. 64, 239-250.

Marzol, M. V., Sánchez Megía, J. L., 2008. Fog water harvesting in Ifni, Morocco. An assessment of potential and demand, Die Erde 139, 97-119.

Monteith J.L. and Unsworth M.H., 1990. Principles of Environmental Physics (2 ${ }^{\text {nd }}$ edition). Routledge, Chapman and Hall, Inc., New-York. 
Moro, M.J., Were A., Villagarcia L., Canton Y., Domingo F., 2007. Dew measurement by Eddy covariance and wetness sensor in a semiarid ecosystem of SE Spain. Journal of Hydrology 335: 295- 302.

Muselli, M., Beysens, D., Marcillat, J., Milimouk, I., Nilsson, T., Louche, A., 2002. Dew water collector for potable water in Ajaccio (Corsica Island, France). Atmos. Res. 64: 297 -312 .

Nikolayev, V.S., Beysens D., Gioda A., Milimouk I., Katiushin E., Morel J.-P., 1996. Water recovery from dew. J. Hydrology 182: 19-35.

Nilsson, T., 1996. Initial experiments on dew collection in Sweden and Tanzania. Sol. Energy Mater. Sol. Cells 40, 23-32.

Olivier, J., Rautenbach, H., 2002. The implementation of fog water collection system in South Africa. Atmos. Res. 64, 227-238.

Olivier, J., Van Heerden, J., 1999. The South African fog water collection project. - WRC Report No 671/1/99. - Pretoria

OPUR, 2015. see www.opur.fr,

Pal Arya, S., 1988. Introduction to Micrometeorology. Academic Press, Inc., San Diego.

Schemenauer, R.S., Cereceda, P., 1991. Fog water collection in arid coastal locations. Ambio 20, 303-308.

Schemenauer R.S., Cereceda, P., 1994. A Proposed Standard Fog Collector for Use in HighElevation Regions. J. Appl. Meteor. Vol 33, 1313-1322.

Sharan, G., 2006. Dew Harvest to Supplement Drinking Water Sources in Arid Coastal Belt of Kutch. Foundation Books, Centre for Environmental Education, India.

Sharan, G., 2011. Harvesting dew with radiation cooled condensers to supplement drinking water supply in semi-arid coastal northwest India. Int. J. Serv. Learn. Eng. 6, 130-150.

Sharan, G., Clus, O., Singh, S., Muselli, M., Beysens, D., 2011. Very large dew and rain ridge collector in Kutch area (Gujarat, India). J. Hydrol. 405, 171-181.

Sharan, G., Beysens, D., Milimouk-Melnytchouk, I., 2007. A study of dew water yields on Galvanized iron roofs in Kothara (North-West India). Journal of Arid Environments 69: 259-269.

Sharan, G., Roy, A. K., Royon, L., Mongruel, A., Beysens, D., 2015. Dew plant for bottling water, Proceedings of the 10th Conference on Sustainable Development of Energy, Water and Environment Systems, SDEWES2015.0762: 1-19.

Tomaszkiewicz, M., Najm, M. A., Beysens, D., Alameddine, I., El-Fadel, M., 2015. Dew as a Sustainable Non-Conventional Water Resource: A Critical Review. Environ. Rev. 23: 1- 
18. DOI: 10.1139/er-2015-0035.

Uclés, O., Villagarcía, L., Moro, M.J., Canton, Y. Domingo, F., 2013. Role of dewfall in the water balance of a semiarid coastal steppe ecosystem. Hydrological Processes 28: 22712280.

Zangvil, A., 1996. Six years of dew observations in the Negev Desert, Israel. Journal of Arid Environments 32: 361-371. 


\section{Highlights}

This one year report of dew and atmospheric precipitations (fog, drizzle, rain) in the semi-arid environment of Baku shows that collecting the dew, fog, drizzle non-conventional water resources can supplement the water resources from rain by a factor on order $20-60 \%$. 